\title{
O TRABALHO DE EMPREGADA DOMÉSTICA E SEUS IMPACTOS NA SUBJETIVIDADE
}

THE WORK OF MAID AND ITS IMPACTS ON SUBJECTIVITY

EL TRABAJO DE EMPLEADA DOMÉSTICA Y SUS IMPACTOS EN LA SUBJETIVIDAD

\author{
Christiane Leolina Lara Silva* \\ José Newton Garcia de Araúijo * \\ Maria Ignez Costa Moreira ${ }^{* * *}$ \\ Vanessa Andrad Barros ${ }^{* * * *}$
}

\begin{abstract}
RESUMO
Este artigo apresenta o contexto histórico do surgimento da categoria da empregada doméstica, seu perfil sociodemográfico e as leis que regulamentam essa ocupação, no Brasil. Trata-se de uma pesquisa basicamente qualitativa, que partiu dos estudos de Le Guillant, relativos à "condição de empregada doméstica". O levantamento de dados baseou-se em entrevistas semiestruturadas com oito empregadas domésticas residentes em Belo Horizonte. Apesar das lutas da categoria e dos avanços legais que regulamentaram a profissão, com a Lei Complementar no 150/2015, constatou-se que o trabalho doméstico ainda é fonte de ressentimentos e humilhações. Os depoimentos das participantes evidenciam os impactos negativos sobre sua subjetividade, já que a profissão é ainda objeto de estigmatização e discriminação, por parte dos empregadores e da sociedade.
\end{abstract}

Palavras-chave: Trabalho; subjetividade; empregada doméstica.

\begin{abstract}
This article presents the historical context of the emergence of maid category, its sociodemographic profile and the laws that regulate this occupation in Brazil. This is basically a qualitative research that began in Le Guillant studies on "maid condition ". The data collection was based
\end{abstract}

\footnotetext{
* Mestra em Psicologia pela Pontifícia Universidade Católica de Minas Gerais (PUC Minas); professora da Faculdade Pitágoras em Belo Horizonte e Contagem-MG; diretora da Educar Psicologia. E-mail: christiane.leolina@gmail.com.

** Graduado em Psicologia (UFMG), mestre em Filosofia (UFMG), Doutor em Psicologia Clínica e Social (Universidade de Paris 7), professor dos cursos de graduação e pós-graduação em Psicologia (PUC Minas), é pesquisador do CNPq e bolsista PPM pela Fapemig E-mail: jinga@uol.com.br

***Psicóloga, doutora em Psicologia Social (PUC-SP), professora da Faculdade de Psicologia da PUC Minas e do Programa de Pósgraduação em Psicologia. Membro do GT ANPEPP Psicologia Sócio-histórica e o contexto brasileiro de desigualdade social. E-mail:maigcomo@uol.com.br

****Graduada em Psicologia e mestre em Administração (UFMG), doutora em Sociologia pela Université de Paris 7 com pósdoutorado no CNAM/Paris. Professora associada do dept. de Psicologia da Universidade Federal de Minas Gerais (UFMG). Coordena o Laboratório de Estudos sobre Trabalho, Cárcere e Direitos Humanos. É membro fundador do Instituto DH: promoção, pesquisa e intervenção é em direitos Humanos e Cidadania. É pesquisadora do CNPq. E-mail: vanessa.abarros@ gmail.com
} 
on semi-structured interviews with eight maids living in Belo Horizonte. Despite the fights of the category and the legal advances that regulate the profession, with the Law 150/2015, it was found that maid job is still a source of resentments and humiliations. The participants statements show the negative impacts on their subjectivity, since the profession is still subject of stigmatization and discrimination, by the employers and by the society.

Keywords: Job; subjectivity; maid.

\section{RESUMEN}

El objetivo de este artículo es mostrar el contexto histórico del surgimiento de la clase de la empleada doméstica, su perfil sociodemográfico y las leyes que regulan esa ocupación, en Brasil. Se trata de una investigación básicamente cualitativa, que partió de los estudios de Le Guillant, relativos a la "condición de empleada doméstica". Los datos fueron levantados por medio de entrevistas semiestructuradas con ocho empleadas domésticas residentes en Belo Horizonte. A pesar de las luchas de la clase doméstica y de los avanzos legales que reglamentaron la profesión, con la Ley Complementaria no $150 / 2015$, se constató que el trabajo doméstico todavía es fuente de resentimientos y humillaciones. Los testimonios de las participantes evidencian los impactos negativos sobre su subjetividad, ya que la profesión es todavía objeto de estigmatización y discriminación, por parte de los empleadores y de la sociedad.

Palabras clave: Trabajo; Subjetividad; empleada domestica.

\section{O EMPREGO DOMÉSTICO E SUA HISTÓRIA NO BRASIL}

história do emprego doméstico, no Brasil, está fortemente associada,
segundo Kofes (2001), à tradição escravocrata. Alugar ou vender escravos
para trabalhos domésticos era prática comum, e o próprio termo "alugado", segundo Viotti da Costa, citado por Gorender (1980), passou a designar o empregado doméstico. E mesmo após a abolição da escravatura, em 1888, os trabalhadores que realizavam serviços domésticos, ainda eram comparados aos escravos (Gorender, 1980). A discriminação relativa ao trabalho doméstico nasce, pois, de sua representação ligada à condição escrava e, consequentemente, à sua desvalorização social. No período escravista, a assimilação da posição social à identidade racial indicava certa equivalência entre a cor e o exercício de certas atividades, ou seja, ser escravo significava ser negro e as atividades realizadas pelos negros, na maioria das vezes, eram atividades desprestigiadas.

A assimilação da condição social da empregada doméstica à sua identidade étnico-racial permanece no Brasil contemporâneo, como mostram os dados 
do Departamento Intersindical de Estatística e Estudos Socioeconômicos (DIEESE, 2013), revelando que a cor ou raça negra é predominante na categoria de empregada doméstica. Entre 2011 e 2014, a proporção de mulheres negras ocupadas nos serviços domésticos, no país, cresceu de $56,9 \%$ para $61,0 \%$. Além disso, 48,9\% das trabalhadoras em serviços domésticos têm baixa escolaridade, em geral com apenas o ensino fundamental incompleto.

Para Kofes (2001) o que distingue a empregada doméstica do escravo, atualmente, é apenas o assalariamento, principalmente no caso daquelas que moram no próprio local de trabalho. Estas se queixam da falta de tempo para realizar suas atividades pessoais, inclusive estudar. Em nossa pesquisa, algumas relataram ter retornado aos estudos apenas depois que os filhos da patroa cresceram, quando passaram a dispor de mais tempo livre à noite. Assim, morar no local de trabalho revela uma situação de maior sujeição e de violação dos direitos legais por parte dos empregadores, entre outros a não-observância da carga horária de oito horas diárias de trabalho, com intervalos de descanso.

Nos dias atuais, encontramos ainda flagrantes resquícios da época da escravidão. Seja exemplo a declaração do economista e ex-ministro da Fazenda, Delfim Neto, que comparava as domésticas a um animal. Em uma entrevista, no programa "Canal Livre" da Rede Bandeirantes, em 2011, ele diz: "Há uma ascensão social incrível. A empregada doméstica, infelizmente, não existe mais. Quem teve este animal, teve. Quem não teve, nunca mais vai ter". Esta declaração teve ampla repercussão na mídia. A ONG "Doméstica Legal" notificou extrajudicialmente o economista, por seu comentário ofensivo às empregadas domésticas.

Outro exemplo, aliás ainda comum, foi à decisão dos moradores de um prédio de luxo, em 27 de outubro de 2011, na cidade de Vitória, em proibir a entrada das empregadas domésticas pela porta da frente do prédio, liberando-lhes apenas a garagem ou a porta dos fundos (Félix, 2011). Ou ainda: a especificação "Dormitório Completo de Empregadas (DCE)", nos projetos arquitetônicos de prédios residenciais, espaço planejado como "depósito", em que mal cabe uma cama, sem janela, com banheiro pequeno, um verdadeiro "quarto de despejo", que reflete a representação social dirigida a essas trabalhadoras. (Azeredo, 2002).

Nas redes sociais também se veiculam agressões contra as domésticas, através de piadas, comentários ofensivos e xingamentos. O perfil do Twitter "A minha empregada" deixa pública essa discriminação, através de inúmeras postagens como "minha empregada trabalha aqui a dois anos, e ela é negra, meu cachorro ainda late toda vez que vê ela ... e eu também" (sic). Ou ainda: "minha empregada ta precisando de bombril em casa, n querer me da um pouco do teu cabelo não? (sic). (Otoni, 2014). 
Segundo Borges e Peixoto (2011) o preconceito supõe a existência de um grupo excluído ou tratado como minoria, o que implica em discriminação social. Para Tajfel (1983) não é a quantidade que define a condição de minoria de um grupo, mas sua posição social, caracterizada por traços depreciados pelos grupos dominantes. Neste sentido, as empregadas domésticas constituem uma minoria social, pois realizam trabalhos socialmente desvalorizados, cuja origem remete à época da escravidão.

A condição de subalternidade das empregadas domésticas está associada, além da condição étnica, à posição de gênero, pois é uma atividade exercida majoritariamente pelas mulheres no espaço privado. Além disso, o trabalho doméstico não é considerado uma atividade produtiva para a qual se necessite uma formação técnica específica. A rotina do trabalho doméstico é marcada por um ciclo interminável de fazer, desfazer e refazer, no interior das casas, e tomada como natural e própria das mulheres, e tudo isso contribui para a invisibilidade tanto deste trabalho, quanto de suas trabalhadoras.

Ao longo da história do trabalho doméstico, também encontraremos iniciativas de suas trabalhadoras que buscam se organizar em associações e sindicatos, em busca de afirmação e garantia de seus direitos. Tal luta é traduzida em normas jurídicas que passamos a discutir.

\section{LEGISLAÇÃO DO EMPREGADO DOMÉSTICO}

A condição de empregado(a) doméstico(a ${ }^{1}$ se revela também na forma como a lei brasileira regulamentava a categoria. A Lei no 5.859, de 11 de dezembro de 1972, regulamentada pelo Decreto-Lei no 71.885, de 09 de março de 1973, dispõe sobre a ocupação de empregada doméstica. Seu artigo $3^{\circ}$ a define como "aquele que presta serviços de natureza contínua e de finalidade não lucrativa à pessoa ou à família no âmbito residencial destas". (Decreto-Lei no 71.885, 1973 p.1).

Em 1988, a Constituição Federal, no parágrafo único do seu artigo 7o, regulou alguns direitos da categoria de empregada doméstica, negando-lhe outros, como salário família, definição de carga horária, na jornada de trabalho (quase sempre excessiva), proteção em relação aos riscos de trabalho, necessidade de equipamentos de proteção individual (EPI's), não-obrigatoriedade de representação sindical que zelasse por seus interesses trabalhistas e conexos, visando garantir-lhes melhores condições de trabalho e vida (Delgado 2008).

1 Apesar de a lei nomear a categoria no masculino "empregado doméstico", utilizamos aqui o feminino, uma vez que a quase totalidade desta profissão é ocupada por mulheres. 
$\mathrm{Na}$ verdade, as empregadas domésticas somente conseguiram equiparar-se às demais categorias profissionais, a partir da Proposta de Emenda à Constituição no 478/2010 (PEC das Empregadas Domésticas) sancionada pela Presidente da República, Dilma Rousseff, através da Lei Complementar no 150, de 01 de junho de 2015. (Brasil, 2015). A partir de então, elas obtiveram novos direitos, como o adicional salarial noturno, intervalos para descanso e alimentação. Outros direitos foram acrescentados em outubro de 2015, como o FGTS, segurodesemprego e salário família. (Brasil:2015)

A aprovação da PEC das domésticas, como ficou conhecida a nova Lei, constitui uma conquista da categoria, entretanto não garante uma mudança efetiva da condição de trabalho, dos direitos legais das empregadas domésticas, nem tampouco a superação dos preconceitos a elas dirigidos. Embora a nova lei tenha entrado em vigor em outubro de 2015, o IBGE mostrava que, no primeiro trimestre de 2016, apenas 34,9\% das empregadas domésticas tinham a carteira assinada, o que lhes retirava direitos trabalhistas como FGTS, seguro desemprego, jornada de trabalho de 44 horas semanais. (IBGE, 2016).

As condições muitas vezes adversas do exercício do trabalho doméstico remunerado exercido pelas mulheres em casas de terceiros; os preconceitos sofridos por essas trabalhadoras; as violações de seus direitos trabalhistas, entre outros elementos, atravessam o processo de subjetivação dessas mulheres e afetam, não raras vezes, a sua saúde. Neste sentido, a experiência do psiquiatra francês Louis Le Guillant comporta reflexões essenciais sobre o seu adoecimento. Outra fonte para a análise dos processos subjetivos decorrentes das atividades das empregadas são as produções literárias e cinematográficas, que evocaremos mais abaixo.

\section{A CONDIÇÃO DE EMPREGADA DOMÉSTICA, SEGUNDO LE GUILLANT}

Um dos autores que escreveu sobre o impacto do trabalho na subjetividade das empregadas domésticas, foi o psiquiatra francês Louis Le Guillant (2006). Em seus textos Incidências psicopatológicas da condição de "empregada doméstica" e $O$ caso das "Irmãs Papin", ambos publicados em 1963, o autor busca desvelar as consequências do trabalho doméstico na saúde mental, ao constatar o aumento de empregadas domésticas entre os pacientes psiquiátricos do hospital em que trabalhava, na França.

No primeiro dos textos citado acima, ele ressalta o papel das determinações "sociais" nos distúrbios mentais: 
Em meu entender, elas constituem um modo de abordagem indispensável à compreensão do fato psiquiátrico. Com efeito, a situação das domésticas (...) constitui uma ilustração, excepcionalmente demonstrativa, de mecanismos psicológicos ou psicopatológicos muito mais gerais. $\mathrm{Na}$ verdade, ela situa-se em uma das dimensões fundamentais da condição humana: dominação versus servidão, dimensão insuficientemente explorada - convém reconhecer - pelo psiquiatra. (Le Guillant, 2006, p. 243).

$\mathrm{Na}$ verdade, continua o autor, a experiência vivida de empregada doméstica, mesmo para aquelas que deixaram essa profissão, deixou ou deixará marcas na sua formação/história, enquanto sujeito. Ele observou que a maior parte das domésticas era oriunda do meio rural. Note-se que, embora em contextos distintos, as empregadas domésticas entrevistadas em nossa pesquisa também tinham origem em cidades do interior e migraram para a capital de Minas Gerais. Le Guillant argumenta que o termo "condição de empregada doméstica", designa "a classe a que pertence uma pessoa na sociedade, por sua fortuna, aptidões, empregos e profissão" (p. 254). Essa condição é que se torna objeto do ressentimento que, associado ao sentimento de humilhação, está bastante presente na fala de suas pacientes. A humilhação se faz visível nos elementos que designam a "condição" de doméstica: o modo de se vestir, o quarto de dormir, até mesmo a linguagem, além das relações de dependência e submissão. Para o autor, o ressentimento e a humilhação constituem o dado primeiro da existência concreta das empregadas domésticas. Elas são também marcadas por sentimentos ambíguos (admiração, inveja, ciúmes, ódio, amor) em relação aos patrões, à afeição que sentem pelas crianças da família, a um relacionamento de proximidade, mas marcado pela dependência e pelo isolamento que impede qualquer tentativa de oposição organizada, como categoria. Assim, seus conflitos são vivenciados e interiorizados apenas individualmente. Le Guillant (2006) não nega a existência de "patrões" gentis ou "amáveis", mas as contradições vivenciadas nas relações de trabalho prevalecem.

Como anunciamos acima, as relaçôes ambivalentes entre as empregadas e suas patroas são objeto de produções literárias e cinematográficas, que revelam a submissão, mas também a resistência e o enfrentamento, por vezes violento, vividos pela empregada doméstica. Tais produções de arte têm como fonte casos reais e são um rico material que possibilita analisar os processos de adoecimento das empregadas. Por exemplo, "O caso das irmãs Papin", duas irmãs e empregadas, que mataram de forma brutal a patroa e sua filha, em 1933, na cidade de Le Mans, França, foi objeto de dois filmes: "O caso das Irmãs Assassinas" e "Entre elas". Ainda no contexto francês, a condição da empregada doméstica já estava evidenciada, à época de Le Guillant, em obras literárias, como na trágica e violenta peça de teatro "Les Bonnes", escrita por Jean Genet em 1947. Mais recentemente, em 2011, foi lançado o filme "Histórias Cruzadas", dirigido pelo 
norte-americano Tati Taylor, relativo a uma história passada nos anos de 1960, mostrando também como domésticas humilhadas se vingam de suas patroas.

No Brasil, encontramos também bons exemplos: em 2001, o filme "Domésticas" dirigido por Fernando Meirelles e Nando Olival, reúne mulheres não atrizes, empregadas domésticas na vida real, que contam suas desventuras em busca de futuro melhor ou da patroa perfeita. As patroas são vistas pela ótica das empregadas domésticas e muitas vezes desqualificadas e criticadas em seus comportamentos e atitudes.

Em 2010, o texto teatral de Noemi Marinho relata a história de "Fulaninha e Dona Coisa": Fulaninha, a moça ingênua do interior, trabalha na casa da intolerante Dona Coisa. Nos seus diálogos, são revelados os sentimentos ambivalentes de rejeição, de raiva, de ternura e de desprezo de uma pela outra.

Em 2015, o filme "Que horas ela volta?", dirigido por Anna Muylaert, também mostra as contradições no relacionamento entre patroa e doméstica, principalmente com a chegada da filha desta, que questiona a condição da mãe. A posição conservadora da patroa se mostra quando ela é confrontada com a aprovação no vestibular da filha da doméstica, em uma universidade pública conceituada e a reprovação de seu filho no mesmo vestibular.

Em todas essas produções artísticas fica evidente a condição de empregada doméstica como um elemento que atravessa o processo de subjetivação, em uma tensão constante, entre a sua afirmação como sujeito autônomo e uma cidadã de direitos, e a sua submissão ao poder dos patróes, ao sentimento de menos valia, gerado por sua atividade laboral desvalorizada.

Tais conflitos podem ser traduzidos no adoecimento psíquico, como mostra Le Guillant; num caso de assassinato, como o das irmãs Papin; nos enfrentamentos e resistências, traduzidos nos modos de realizar as tarefas domésticas ou no modo pelo qual elas se relacionam e se referem entre pares a seus patróes, como relatados nos filmes que foram citados.

\section{A FUNÇÃO E O SENTIDO DO TRABALHO}

Se dissemos que o trabalho da empregada doméstica impacta sua subjetividade, importa discutir, mesmo brevemente, aspectos relativos ao conceito de trabalho. Observe-se, inicialmente, com Schwartz (2011, p. 20), que "o trabalho é uma realidade enigmática, e que uma definição clara do trabalho será sempre um problema”. O autor refere-se à necessidade de se compreender a atividade de trabalho, por detrás do que nele é visível. Essa questão esbarra em três impasses significativos: o nascimento do trabalho, a impossibilidade de simplificação do trabalho e as ilusões da divisão do trabalho. 
Em relação ao "nascimento do trabalho", existe a propensão a limitar o seu aparecimento à época da Revolução Industrial e ao assalariamento, o que permitiria diferenciar "o trabalho" do "fora do trabalho" ou do "não trabalho", (Schwartz, 2011). Isso equivale a reduzi-lo a uma relação mercantil e esquecer outras significações, ou seja, suas dimensões antropológicas e todas as outras atividades humanas que não passam necessariamente pela questão mercantil. (Schwartz, 2011). O segundo impasse é a impossibilidade de simplificação do trabalho, limitando o seu alcance conceitual e da experiência, reduzindo-o às atividades assalariadas ou a tarefas desprovidas das dimensões criativas. $\mathrm{O}$ terceiro, impasse diz respeito às ilusões da divisão do trabalho, já presente em sua simplificação. Schwartz, afirma: "todo sujeito, todo grupo humano no trabalho, é um centro de vida, uma tentativa de apropriação do meio e sua vida no trabalho não é uma cerca separada de sua ambição de vida global. " (Schwartz, 2011, p. 30). Nessa perspectiva, a suposta divisão ou simplificação do trabalho poderá eliminar a análise do que é o tornar-se sujeito, em sua totalidade.

Para Dominique Lhuilier (2013), por sua vez, é por meio do trabalho que o sujeito busca sua identidade. $\mathrm{O}$ trabalho o impele à criatividade, a manifestar e a fazer reconhecer sua singularidade. É através dele que o sujeito vivencia a dimensão do reconhecimento, pois a satisfação de ver-se em sua própria obra não pode ocorrer sem o olhar ou o reconhecimento do outro. Trabalhar é também estar inscrito socialmente em um grupo de pertencimento, que garante a validação das próprias práticas. Esse pertencimento, através da identificação, "permite uma articulação entre o pulsional e o social, entre a história singular de um sujeito e a história social do grupo de referência” (Lhuilier, 2013 p. 485).

É o trabalho que permite ao sujeito "sair de si", estabelecendo relações e construindo algo com e para o outro. Nesse sentido, a relação sujeito-sociedade encontra-se na base da compreensão do mundo do trabalho e do sujeito trabalhador. Ademais, ao mesmo tempo em que o homem (ser humano genérico) transforma a natureza, ele se autotransforma, dada a sua relação com a cultura, a identificação com o grupo, a autorrealização e o sentimento de autoestima, que decorre do trabalho (Carreteiro \& Barros, 2011).

Lembremos ainda que, para Lhuilier (2014), o trabalho ultrapassa o estatuto de atividade, tornando-se também uma instituição, com dupla funcionalidade, social e psíquica. Como instituição, ele contribui para a formação da sociedade e da cultura, mediatiza as relações, orienta as práticas e serve como referência, na elaboração do sentido da praxis. Como elemento da formação psíquica, ele mobiliza investimentos, representações e valores, sustentando a identificação do sujeito com suas açōes. Enfim, como instituição, o trabalho legitima atividades sociais, como cuidar, educar, produzir, governar, vigiar. Neste sentido, ele é 
produto de uma história, cujas orientaçôes transmite e reproduz, mas também inova, pois não se reduz ao instituído, às instâncias dominantes. Ele é tecido por forças instituintes, questionando as práticas e contradições sociais, construindo novas regras sociais. Neste sentido, "trabalhar não se limita a se perguntar ou a dizer como fazer. É também, fundamentalmente, pensar o "por que fazer" e contemplar a própria atividade, através daquilo que se busca fazer." (Lhuilier, 2014, p.15).

Após as breves discussões sobre o contexto histórico e legal da condição da empregada doméstica, e apoiados nos conceitos de trabalho trazidos por Schwartz (2011) e Lhuilier (2014), descrevemos a pesquisa realizada com empregadas domésticas em Belo Horizonte (MG).

\section{A PESQUISA}

Nossa investigação se apoiou na abordagem qualitativa, vista como um método que se aplica ao estudo da história, das representações grupais, percepções, opiniōes, enfim, ela se volta para o universo dos significados, das crenças e valores, em função das interpretações que as pessoas fazem de si e do mundo em que vivem (Minayo, 2010). Tais elementos pressupõem elaborações reflexivas, partilhadas num determinado contexto social.

Para a pesquisa de campo, foram realizadas entrevistas individuais com oito empregadas domésticas, residentes em Belo Horizonte, Minas Gerais, maiores de 18 anos. Algumas delas foram recrutadas e entrevistadas em escolas municipais e estaduais que ofereciam o Ensino Fundamental ou Ensino Médio, no turno da noite. As demais foram selecionadas através de indicações.

Das entrevistadas, 75\% eram negras, o que reafirma que a condição de raçaetnia é um fator histórico e predominante na categoria de empregada doméstica. Nenhuma delas nasceu em Belo Horizonte, vieram do interior de Minas ou da Bahia, apesar de algumas trabalharem, há mais de 30 anos, na cidade.

As entrevistas, semiestruturadas, foram realizadas em junho de 2011 e tiveram uma duração média de 30 minutos, tendo sido gravadas e transcritas, buscando-se anotar as entonaçōes de voz e as pausas, nas falas. Para garantir o anonimato, as participantes foram representadas por nomes fictícios. A pesquisa foi aprovada pelo Comitê de Ética da PUC-Minas (CAAE 0142.0.213.000-11) e as entrevistadas assinaram o Termo de Consentimento Livre e Esclarecido. 


\title{
6. CATEGORIAS DE ANÁLISE
}

As categorias de análise foram construídas a partir da leitura das entrevistas, estabelecendo-se articulações com o referencial teórico do estudo, segundo os núcleos temáticos: escravidão, discriminação, não pertencimento à família e ressentimento. Alguns elementos dessa análise são discutidos nos tópicos que se seguem.

\subsection{Escravidão}

Nas entrevistas, foi possível constatar a referência à escravidão, através de relatos sobre a extensa carga horária e baixos salários:

\begin{abstract}
Nós, empregadas domésticas, não temos direito ao Fundo de Garantia, pelo menos não tinha, não sei agora. Comigo não tem problemas. Eu sei que tem empregadas que trabalha como escrava, recebe um salário mixuruco, são exploradas. Aonde você vai, você vê, tem muitas pessoas que exploram, que acha que tem que acordar cedo e que tem que ir até às 10 da noite trabalhando e é obrigada e que acha que tá morando na casa, porque almoça, porque lancha, porque toma café, toma banho, acha que tem obrigação por isso tudo. Aí explora, explora com força. (Joana).
\end{abstract}

Eu trabalho muito tempo com ela, mais tem muitas coisas que não devia ser. Tem horário de começar, mas não tem horário de terminar. Trabalho todos os finais de semana e todos os feriados. (Margarida).

A história do surgimento da categoria de empregada doméstica está refletida no cotidiano dessas trabalhadoras, que evoca traços do passado escravagista. Apesar do salário, o sentimento de exploração é permanente, devido à carga excessiva de trabalho. Mesmo com as mudanças na legislação, através da Emenda Constitucional no $72 / 2013$, que limita a jornada de trabalho a 44 horas semanais, as jornadas prolongadas não cessaram. Segundo o DIEESE (2015), no ano de 2014, na cidade de Recife, $67 \%$ das mensalista domésticas trabalharam acima de 44h semanais; em São Paulo, esse índice foi 22\%.

\subsection{Discriminação}

Segundo Le Guillant (2006), a condição de empregada doméstica está na origem do ressentimento e da humilhação, pois sua atividade a coloca em um lugar social desqualificado. Esse estado afetivo é revivido em depoimentos como o que se segue: 
Eu tenho preconceito em falar que sou empregada doméstica. Eu sou empregada de fulano, eu não gosto desse termo, eu odeio. Porque nossa profissão não é uma profissão, as pessoas não veem com bons olhos, por exemplo, quando você sai, você conhece uma pessoa, a pessoa te pergunta: o que é que você faz? Se eu falar sou empregada, ele fala: legal. Eu admiro essa profissão. Mas mentira, né? Não admira nada, pode até achar você legal, mas por causa da sua profissão, a pessoa não fica com você. (Joana)

Joana diz assumir sua profissão apenas para pessoas de sua intimidade, resguardando-se em eventos sociais, o que provoca profundo mal-estar, por sentir o peso do preconceito, também partilhado por Luiza, que acrescenta a este o desprezo e a ausência de reconhecimento:

Assim, eu tenho um pouco de vergonha em falar, mas eu falo. Mas, eu mesmo, às vezes, eu tenho um pouco de preconceito. As pessoas têm preconceito, elas falam assim: doméstica não faz nada, só arruma a casa e mais nada. Não valorizam, não sabem como que é. (...) eu acho que isso acontece é por causa da categoria, minha mãe reclama, minhas irmãs reclamam. É de categoria. O que acho ruim é isso, é levantar e não dar um bom dia e já mandar fazer um serviço. Ás vezes, você fica até mais tarde e ninguém reconhece. (Luíza).

A experiência vivida como empregada doméstica deixa marcas evidentes na construção de sua subjetividade, construída no contato conflitante com os empregadores e na solidariedade interna ao próprio grupo, ou seja, ao coletivo de trabalho do qual ela faz parte. Neste sentido, segundo Le Guillant (2006), não seria apropriado querermos separar o que parece ser do sujeito e o que constitui um traço do grupo, uma vez que as discriminações e humilhações fazem parte das histórias individuais e coletivas da categoria.

\subsection{Não-pertencimento à família}

A expressão "membro da família" é utilizada pelos patrões como argumento para justificar a relação de confiança, supostamente essencial ao emprego doméstico, como escreve Gusmão (2007). Essa confiança é até mesmo sugerida pela legislação trabalhista, pois, na relação com a empregada doméstica, a pessoalidade tem destacada intensidade, o que deveria resultar em respeito à figura do trabalhador (Delgado, 2008). No entanto, em seus depoimentos, nenhuma doméstica considerava-se membro da família:

Mas não é membro da família. Falava assim, você é filha da casa. Não fale que sou da família, não sou da família. Eu sou uma empregada doméstica, eu não gosto de fachada, eu gosto das coisas certas. (Margarida). 
Em festa de aniversário meu, eu não faço festa para mim. Isso me incomoda. Só a família da casa. Eu faço para o povo da casa. Vamos supor, eu tenho bastantes amigos, amigas. Amigas de coração que me tratam bem, que eu falei assim: gente eu podia tanto levar esse amigo para almoçar em casa. Mas eu não tenho essa liberdade, eu não sou da família. (Patrícia).

Não sinto que sou de casa. Não é mesmo, às vezes até as crianças gritam, "faz isso assim”, eu não faço, falo assim: fala com educação comigo. (Luíza).

De acordo com Kofes (2001), ser nomeada como "membro da família" é uma expressão que não soa como real para as domésticas. Trata-se apenas de um artifício ou uma estratégia ideológica, da parte da patroa, obrigada a aceitar uma estranha que vai compartilhar, em certos aspectos, a vida da família:

A expressão "membro da família” expressa um mecanismo ideológico fundamental nessa relação, mas não no sentido de que os agentes envolvidos estejam iludidos por um real falso. Talvez nenhuma das parceiras (polares) dessa interação acredite no que afirma essa frase, mas nesse caso não se trata de acreditar ou não. O efeito ideológico dessa afirmação, do ponto de vista da patroa, é que ela torna possível a aceitação de uma pessoa socialmente estranha dentro de casa, compartilhando o cotidiano da família. Trata-se de uma justificativa, em seus próprios termos, quase como uma estratégia de "efeito adequado". Essa expressão, no que concerne às empregadas, expressa outra estratégia, que é abrir vias de acesso que estruturalmente ainda lhe são fechadas. (Kofes 2001 p. 178).

\subsection{Ressentimento}

Neste estudo, também, ficou bastante patente o ressentimento com a patroa. Vejamos o seguinte relato:

Eu fiquei magoada com minha patroa, porque sempre fui doida para estudar e nunca podia, por causa do trabalho. Tinha que cuidar das crianças que ainda eram pequenas e o serviço era muito. Aí, um dia, eu estava conversando com uma amiga que meu sonho era estudar, os meninos já cresceram, aí você vai se sentindo sozinha, porque quando os meninos eram pequenos a minha vida não era vazia, era cheia, era uma confusão o dia inteiro. Então ouvi minha patroa falar com uma amiga: não faço muita questão de pôr ela na escola, porque ela é muito inteligente. Eu fiquei totalmente chateada. Eu falei assim: puxa vida, que pessoa; uma pessoa que não quer ver você crescer. (Patrícia).

Às vezes, eu sinto o preconceito por parte dos patrôes, tipo assim, tenho que pôr o almoço na mesa e fechar a porta. Eles levantam, não te dão um bom dia e falam para já fazer algo. Eles não sabem do meu aniversário. (Luíza)

Minha patroa é que resolvia tudo para mim, tudo, se precisa mandar um dinheirinho para minha família, ela resolvia. Teve um dia que tive um arranca-rabo com ela, eu resolvi que 
a partir daquele dia eu que iria resolver todos os meus problemas. Depois que aposentei, resolvi abrir uma conta. Aí fui ao gerente e ele me falou que podia abrir conta. Aí fui lá, e resolvi tudinho, assinei tudinho, ainda fiz um consórcio. Aí cheguei em casa com papelada toda pronta. Aí a patroa falou: que bobagem você fez. Aí não falei nada, só pensei, bobagem era se eu tivesse com dinheiro e gastando o dinheiro como estava fazendo. (Margarida)

Em todos os depoimentos, destaca-se a referência ao ressentimento, à humilhação e às contradições vividas pelas participantes, em relação aos patrões e membros da família. Para Le Guillant (2006) a frustração, a humilhação, o sentimento de inferioridade, a dependência, a fadiga e o ressentimento são parte da situação concreta que é dramática e que acompanha a condição de empregada doméstica.

Além das questões jurídicas, relativas aos baixos salários e horas-extra não remuneradas, o ressentimento e a humilhação estão intensamente presentes nas falas das domésticas. Tais sentimentos resultam, principalmente, da enorme desigualdade, no sistema de trocas materiais e simbólicas entre a empregada e os patrôes. Isto se refere ao que é dado, em termos de prestação de serviço e dedicação pessoal, e o recebido, no tocante ao salário e às formas de tratamento, marcadas pela desconsideração ou desvalorização. As contradições vividas por essas trabalhadoras, pelo fato de serem, ao mesmo tempo, empregada e alguém que mantém, às vezes, até certa intimidade com as pessoas da casa, caracterizam uma forma singular de alienação no trabalho. Assim, a ambiguidade nas relações pode mascarar a realidade da exploração e da dominação, próprias do trabalho doméstico.

\section{CONSIDERAÇÕES FINAIS}

Ao longo da pesquisa, vimos que, para se compreender a condição da empregada doméstica, é importante a contribuição de várias disciplinas, conforme os pressupostos da psicologia do trabalho. Isso nos levou a ampliar o conceito de trabalho, ligando-o a contextos históricos e sociais, a fim de melhor compreendermos a "condição de empregada doméstica", expressão cara a Le Guillant (2006), que remete à complexidade de uma profissão, mas que, devido à sua representação socialmente desqualificada, poderíamos incluir no vasto rol das profissões consideradas como "trabalho sujo" (Hugues, 1996; Lhuilier, 2014). Com efeito, o trabalho doméstico, datado historicamente na escravidão, carrega o peso do preconceito e da desvalorização, materializada na perda da igualdade dos direitos trabalhistas, só recentemente reparada, através da aprovação tardia da PEC das empregadas domésticas. 
Apesar da mudança neste marco legal, as relações concretas de trabalho, as representações sociais e as atitudes dos patrões não mudaram automaticamente, como atestam tanto os relatos das participantes quanto alguns dados documentais apresentados. Assim, permanece o ressentimento das empregadas domésticas, em face da desigualdade nas relações de trocas materiais e simbólicas, associada ao sentimento institucionalizado de humilhação (uso de roupas especiais ou uniformes, que não lhes permite se misturarem à "outra classe" dos patrões; quarto precário, entrada por elevador dos fundos; jornada excessiva de trabalho; piadas ofensivas, através de redes sociais).

Todos esses dados evidenciam que o trabalho de empregada doméstica tem impactos negativos em sua subjetividade ou, melhor dizendo, em sua existência, tomada como uma totalidade. A construção da própria identidade, através do trabalho, bem como a busca do reconhecimento, se confundem, no caso, com o próprio sentimento de vulnerabilidade social, econômica, profissional e, finalmente, existencial. No entanto, percebemos que as empregadas domésticas que foram entrevistadas para a pesquisa, expressam em suas narrativas uma potencialidade reflexiva sobre a sua própria condição.

Como já assinalamos a mudança do marco legal não é suficiente para operar a mudança das representações sociais sobre as empregadas domésticas. No entanto, o marco legal confere o reconhecimento dos direitos dessas trabalhadoras e tais direitos só puderam ser reconhecidos por meio de sua própria luta. Neste sentido, a lei reflete um movimento de transformação social, e a desobediência da lei por parte dos patrôes dá visibilidade à complexidade das tensóes no campo do trabalho doméstico. 


\section{REFERÊNCIAS}

Azeredo, S. (2002). A ânsia, o sino e a transversalidade na relação entre empregadas e patroas. Cadernos Pagu, (19). Recuperado a partir de http://www.scielo.br/ pdf/cpa/n19/n19a14.pdf.

Borges, L. de O. \& Peixoto, T. P. (2011). Ser operário da construção civil é viver a discriminação social. Revista Psicologia: organização e trabalho, 11 (1). Recuperado a partir de https://periodicos.ufsc.br/index.php/rpot/article/ view/22244.

Carreteiro, T. C. O.; Barros, V. A. (2011). Clínicas do trabalho: contribuições da psicossociologia no Brasil. In P. F Bendassolli \& L. A. P. Soboll (Orgs.), Clínicas do trabalho: novas perspectivas para compreensão do trabalho na atualidade (pp.208-226). São Paulo: Atlas.

BRASIL. (1988). Constituição da República Federativa do Brasil de 1988. (1988, 5 de dezembro). Brasília. Recuperado a partir de http://www.planalto. gov.br/ccivil_03/constituicao/constituicao.htm

BRASIL. (1973). Decreto-Lei no 71.885, de 09 de março de 1973. (1973, 09 de março). Dispõe sobre a profissão de empregado doméstico. E dá outras providências. Brasília. Recuperado a partir de http://www2.camara.leg. br/legin/fed/decret/1970-1979/decreto-71885-9-marco-1973-420205publicacaooriginal-1-pe.html.

BRASIL (2015). Lei Complementar no 150, de 01 de junho de 2015. Dispõe sobre o contrato de trabalho doméstico; altera as Leis $n^{\circ} 8.212$, de 24 de julho de 1991, no 8.213 , de 24 de julho de 1991, e n ${ }^{\circ} 11.196$, de 21 de novembro de 2005; revoga o inciso I do art. $3^{\circ}$ da Lei $n^{\circ} 8.009$, de 29 de março de 1990, o art. 36 da Lei $\mathrm{n}^{\circ} 8.213$, de 24 de julho de 1991 , a Lei ${ }^{\circ}{ }^{5.859}$, de 11 de dezembro de 1972, e o inciso VII do art. 12 da Lei n ${ }^{\circ}$ 9.250, de 26 de dezembro 1995; e dá outras providências. Brasília, DF: Presidência da República. Recuperado a partir de http://www.planalto.gov.br/ccivil_03/leis/LCP/Lcp150.htm.

Delgado, M. G. (2008). Curso de direito do trabalho (7a ed.). São Paulo: LTr.

DIEESE - Departamento Intersindical de Estatística e Estudos Socioeconômicos (2013, agosto). O emprego doméstico no Brasil. Estudos e Pesquisas, 68. São Paulo: DIEESE. Recuperado a partir de https://www.dieese.org.br/ estudosetorial/2013/estPesq68empregoDomestico.pdf 
Trabalho doméstico remunerado. Pesquisa de Emprego e Desemprego. São Paulo: DIEESE (2015) Recuperado a partir de www.dieese.org.br/ analiseped/2014/2014EmpregoDomestico.pdf.

Doméstica Legal. (2011). ONG quer desculpa de Delfim por comparar domésticas a animais. (2011, 05 abril). Folha de São Paulo. Recuperado a partir de http://www1.folha.uol.com.br/cotidiano/2011/04/898757-ongquer-desculpa-de-delfim- por-comparar-domesticas-a-animais.shtml.

Félix, T. (2011, 26 outubro). Domésticas obrigadas a entrar pela garagem na Praia do Canto. Gazeta Online. Recuperado a partir de http://gazetaonline.globo. com/_conteudo/2011/10/noticias/a_gazeta/dia_a_dia/1005286-domesticasobrigadas-a-entrar-pela-garagem-na-praia-do-canto.html

Gorender, J. (1980). O escravismo colonial. São Paulo: Ática.

Gusmão, X. (2007). Novos Direitos do Doméstico. Âmbito Jurídico, 10(40). Recuperado a partir de http://www.ambito- juridico.com.br/site/index.php?n_ link=revista_artigos_leitura\&artigo_id=1761.

Hugues, E. (1996). Le regard sociologique. Essais choisis. Paris: EHESS.

(IBGE) - Instituto Brasileiro de Geografia e Estatística. (2016). Pesquisa nacional por amostra de domicílios. Rio de Janeiro: IBGE. Recuperado a partir de ftp:// ftp.ibge.gov.br/Trabalho_e_Rendimento/Pesquisa_Nacional_por_Amostra_ de_Domicilios_continua/Trimestral/Comentarios/pnadc_201601_trimestre_ comentarios_20160519_113000.pdf

Kofes, S. (2001). Mulheres, mulheres-identidade, diferença e desigualdades na relação entre patroas e empregadas domésticas. Campinas, SP: UNICAMP.

Le Guillant, L. (2006). Incidências psicopatológicas da condição de empregada doméstica. M. In E. A. Lima (Org.). Escritos de Louis Le Guillant: da ergoterapia à psicopatologia do trabalho. Rio de Janeiro: Vozes, p. 242-286.

Lhuilier, D. (2013). Trabalho. Psicologia \& Sociedade 25(3). Recuperado partir de http://www.ufrgs.br/seerpsicsoc/ojs2/index.php/seerpsicsoc/article/ view/3642/2260.

Lhuilier, D. (2014). Introdução à psicossociologia do trabalho. Cadernos de Psicologia do Social do Trabalho (17). Recuperado a partir de http://www. revistas.usp.br/cp st/article/view/80628 
Minayo, M. C. S. (2010) O desafio do Conhecimento: pesquisa qualitativa em saúde (12a ed.) São Paulo: Hucitec.

Otoni, I. (2004, 21 maio). Perfil do Twitter denuncia preconceito contra empregadas domésticas. Forum. Recuperado a partir de http://www. revistaforum.com.br/twitter-denuncia-preconceito-contra-empregadasdomesticas/

Schwartz, Y. (2011). Conceituando o trabalho, o visível e o invisível. Trabalho, Educação e Saúde, 9(1). Recuperado a partir de http://www.scielo.br/pdf/tes/ v9s1/02.pdf

Tajfel, H. (1982). Grupos humanos e categorias sociais (vol. 2). Lisboa, Portugal: Livros Horizontes. 